\title{
The Prevent-Predict-Prescribe Model: Defeating Depression Among Asian Nursing Students
}

\author{
Mrs. Chandrani Isac ${ }^{1}$, Mr. Joshy Abraham ${ }^{2}$ \\ ${ }^{I}$ (Lecturer, College of Nursing/Sultan Qaboos University, Muscat, Oman) \\ ${ }^{2}$ (Lecturer, College of Nursing/Sultan Qaboos University, Muscat, Oman)
}

\begin{abstract}
Background: Depression is exceeding prevalent worldwide and its impact on the personal, professional and social life of an individual is well documented in literature. Adolescents are more prone to depression owing to their hormonal turbulences and their need to establish their role identity. Nursing students are at greater risk for depression owing to the vast majority of them being adolescents and also due to the enormous lifestyle change demanded by the profession. This review was undertaken to ascertain from existing empiral evidences, the prevailing standards of depression; its associated factors and strategies implicated by researchers to prevent the permeation of depression among Asian nursing students.

Methods: A systematic review of literature based on depression among nursing students in Asian countries, published between 2010 and 2014 from selected databases was done. A total of 6 articles were included in the review.

Results: Three significant themes emerged from the findings of the reviewed studies. The key to curbing depression among student nurses is with nursing educators, self-preparedness of the nursing students and the evolution of a holistic system to help nursing students adapt to the profession are the essential components to put an end to the escalating pace of depression among nursing students in Asia.

Conclusion: A model conceptualizing these themes has also been generated to explicitly envision the benefits of implementing these themes as improved competence, commitment and collaboration as professional nurses.

Keywords: nursing students, depression, self-esteem, nursing educators, self-preparedness, holistic system, teacher-student interactions
\end{abstract}

\section{Introduction}

Depression is a short-lived emotional response to challenges in everyday life. On the global front, depression is a common illness affecting an estimated 350 million of people.It is a latent disorder with the potency of becoming a major health problem if it is long-lasting or if it is of moderate or severe intensity. This morbid nature of depression is termed as a Major Depressive Episode (MDE). A MDE is defined as a period of at least two weeks in the past year when a person self-reports an experience of a depressed mood or loss of interest or pleasure in daily activities and has had at least four additional symptoms (such as problems with sleeping, eating, energy, concentration, and feelings of self-worth).As described in the 5th edition of the Diagnostic and Statistical Manual of Mental Disorders (DSM-V), MDE with severe impairment has been reported to cause the highest level of impairment in at least one major role domain (home, school/work, family relationships or social life). At its worst, depression can lead to suicide.

\section{Background}

Though the prevalence of depression is on the increase, the burden of depression among the adolescents is of concern. With reference to Perou'ssurvey among 45000 adolescents aged between 12 and 17 revealed the prevalence of major depression at 8 percent. There are many reasons elaborated in literature for the escalating prevalence of depression in this age group. Adolescents are in a stage of life where they need to move from dependent enclosures to independency. Furthermore, their physical growth necessitates them to keep a check on their moral and societal boundaries. An additional challenge faced by this age group is for them to unmask their role identity and showcase to the world their capabilities and potentials.Extra-personal factors like a family history of mental illness and exposure to other adolescents who have committed suicide are also cited in literature to provoke depression among adolescents. The impulsivity possessed by the adolescents drives them to self-injurious behaviors. Depression in adolescence may also lead to behavioral problems such as irritability or moodiness, fighting, defiance, skipping school, running away, drug use, sexual experimentation, and poor grades.Thus the period of adolescence is the phase in which a person is comprehensively molded to face the battles of their future. This challenging phase of life can cause an individual to slide into the depressive mood, if and when their path to success is inhibited or intimidated. 
Most nursing students begin their professional career during their adolescence. The clinical integrated nature of the course design the accountability laid on these student and the perceived high academic load places these students at greater risk for depression. Furthermore, nursing students are strategically placed in the health care delivery system, where they need to possess assertiveness, collaborative and critical thinking skills. The acquisition of these virtues requires the person to nurture a sound mind and positive self-esteem. Literature survey clearly exemplified the extensive research done in this domain. A systematic review of the available literature was sought to magnify the current trend of depression among nursing students.

\section{Objectives}

To identify the prevailing standards of depression and its associated factors among Asian nursing students from existing empirical evidences

To identify the strategies implicated by researchers to prevent the permeation of depression among Asian nursing students from existing empirical evidences

To synthesize a framework to prevent, predict and prescribe for depression among Asian nursing students

\section{Methods}

Search Strategy: the review included article published from 2010 to 2014. The following electronic databases were searched CINAHL, Medline, SCOPUS, OVID and EBSCO. Key words used included depression, nursing students, hopelessness, worthlessness, helplessness and self-esteem.

Inclusion Criteria:for the study were: (a) nursing students at a basic level of education (b) studies which utilized a standardized tool to measure depression and/or mood and/or self-esteem and/or anxiety and/or stress and/or spiritual well-being (c) English language (d) quantitative research articles

Exclusion Criteria: included studies which focused on suicide and suicide ideations

Critical appraisal: quality assessment of the selected studies was done by experts in the field of psychiatry nursing;TheMethodologicalquality of the studies chosen was ranked utilizing the rating system for hierarchy of evidence: quantitative questions (Table 1). Meta-analysis was not performed due to the variations in tools and methods used.

Table 1: Rating System for the Hierarchy of Evidence: Quantitative Questions

\begin{tabular}{|l|l|}
\hline Level & Definition \\
\hline Level I & $\begin{array}{l}\text { Evidence from a systematic review of all relevant randomized controlled trials [RCT's], or evidence-based } \\
\text { clinical practice guidelines based on systematic reviews of RCT's }\end{array}$ \\
\hline Level II & Evidence obtained from at least one well-designed Randomized Controlled Trial [RCT] \\
\hline Level III & Evidence obtained from well-designed controlled trials without randomization, quasi-experimental \\
\hline Level IV & Evidence from well-designed case-control and cohort studies \\
\hline Level V & Evidence from systematic reviews of descriptive and qualitative studies \\
\hline Level VI & Evidence from a single descriptive or qualitative study \\
\hline Level VII & Evidence from the opinion of authorities and/or reports of expert committees \\
\hline
\end{tabular}

Data Extraction:a total of 6 journal articles were included in the review. All articles selected for review were entered into a bibliographic software package (Endnote Version 7). Synthesis of data was presented in text and tabular format.

\section{Results}

Table 2 summarizes the studies reviewed for the current study. The studies selected were done in different countries in the Asian continent, which included China, India, Korea, Oman, Taiwan and Thailand. Five of the six studies selected were categorized under level VI of the Rating System for the Hierarchy of Evidence: Quantitative Questions. Among the studies categorized under level IV, four studies had employed cross-sectional design and one study had adopted the exploratory design. One study was of quasi experimental design and was categorized under level III.

Table 2: Essentials of the Literature Review of Depression Among Asian Nursing Students

\begin{tabular}{|c|c|c|c|c|}
\hline $\begin{array}{l}\text { Author } \\
\text { [Year] }\end{array}$ & $\begin{array}{l}\text { Participants } \\
\text { [Sample Size } \\
\text { n] }\end{array}$ & Measuring Instruments & Results & $\begin{array}{l}\text { Level of } \\
\text { Evidence }\end{array}$ \\
\hline $\begin{array}{l}\text { Ratanasirip } \\
\text { ong. P } \\
{[2012]}\end{array}$ & $\begin{array}{l}\text { Undergraduate } \\
\text { Nursing } \\
\text { students } \\
{[n=110]}\end{array}$ & $\begin{array}{l}\text { The State Anxiety } \\
\text { Scale from the State- } \\
\text { Trait } \\
\text { Anxiety Inventory } \\
\text { The Center for } \\
\text { Epidemiology Studies- } \\
\text { Depression Scale } \\
\text { [CES-D] }\end{array}$ & $\begin{array}{l}47 \% \text { of the participants were found to possess } \\
\text { at least a mild level of depression } \\
\text { Lower mean scores for stress was obtained, } \\
\text { and stress was positively correlated with } \\
\text { anxiety and depression } \\
\text { Higher mean scores for self-esteem was noted, } \\
\text { and self-esteem was negatively correlated with } \\
\text { anxiety and depression }\end{array}$ & Level VI \\
\hline
\end{tabular}




\begin{tabular}{|c|c|c|c|c|}
\hline & & $\begin{array}{l}\text { The Rosenberg Self- } \\
\text { Esteem Scale [RSE] } \\
\text { The Perceived Stress } \\
\text { Scale [PSS] } \\
\text { The Multidimensional } \\
\text { Scale of Perceived } \\
\text { Social Support } \\
\text { [MSPSS] }\end{array}$ & $\begin{array}{l}26 \% \text { of the participants had reported anxiety } \\
\text { Mean scores for social support was also higher } \\
\text { in this group, which was not a predictor of } \\
\text { anxiety, and was negatively correlated with } \\
\text { depression }\end{array}$ & \\
\hline Lee [2014] & $\begin{array}{l}\text { Nursing } \\
\text { Students } \\
{[\mathrm{n}=518]}\end{array}$ & $\begin{array}{l}\text { Spiritual Well-Being } \\
\text { Scale [SWBS] } \\
\text { Beck Depression } \\
\text { Inventory [BDI] } \\
\text { Korean version of } \\
\text { Perceived Stress Scale } \\
\text { [PSS] }\end{array}$ & $\begin{array}{l}\text { The mean scores for Existential Well-Being } \\
{[E W B] \text { was higher than that for Spiritual Well- }} \\
\text { Being [SWB] and Religious Well-Being } \\
{[R W B] \text {. SWB was negatively correlated with }} \\
\text { perceived stress and depression } \\
\text { The participants mean score for depression } \\
\text { was within the optimum level of well being } \\
\text { Lower mean scores for stress also was } \\
\text { documented } \\
\text { The students with higher SWB, EWB \& RWB } \\
\text { scores were satisfied with their career choice } \\
\text { and were confident of their future employment }\end{array}$ & Level VI \\
\hline $\begin{array}{l}\text { Hsaio } \\
{[2012]}\end{array}$ & $\begin{array}{l}\text { Nursing } \\
\text { Students from } \\
\text { the } 5^{\text {th }} \text { year of } \\
\text { Associate } \\
\text { Degree } \\
\text { Program, } \\
\text { Experimental } \\
\text { group } \quad[n=39] \\
\text { and Control } \\
\text { group [n=46] }\end{array}$ & $\begin{array}{l}\text { Spiritual health scale } \\
\text { Perceived clinical } \\
\text { practice }\end{array}$ & $\begin{array}{l}\text { When comparing the clinical practice stress } \\
\text { scores, the experimental group demonstrated } \\
\text { decrease in scores between week } 1 \text { and } 10 \text {; and } \\
\text { the control group depicted an increase in their } \\
\text { stress scores during the same tenure } \\
\text { Similarly the experimental group scored better } \\
\text { in the final clinical practice than the control } \\
\text { group }\end{array}$ & Level III \\
\hline $\mathrm{Xu}$ [2014] & $\begin{array}{l}\text { Nursing } \\
\text { Students } \quad[n= \\
729]\end{array}$ & $\begin{array}{lr}\text { Center } & \text { for } \\
\text { Epidemiologic } & \text { Studies } \\
\text { Depression } & \text { Scale } \\
{[\text { CES-D] }} & \end{array}$ & $\begin{array}{l}\text { Nearly } 23 \% \text { of the nursing students had } \\
\text { depression } \\
\text { Academic, personal and interpersonal traits of } \\
\text { the participants were significantly associated } \\
\text { with depression }\end{array}$ & Level VI \\
\hline $\begin{array}{l}\text { Chatterjee } \\
{[2014]}\end{array}$ & $\begin{array}{l}\text { Bachelor of } \\
\text { Science } \\
\text { Nursing } \\
\text { Students } \\
{[n=180]}\end{array}$ & $\begin{array}{l}\text { Beck } \\
\text { Depression Inventory }\end{array}$ & $\begin{array}{l}\text { Depression was found in } 63.9 \% \text { of the } \\
\text { students. The majority [42.2\%] had a mild } \\
\text { degree of depression and 20.6\% had a } \\
\text { moderate degree of depression } \\
\text { Depression scores were higher among first- } \\
\text { year students and gradually declined in senior } \\
\text { classes. } \\
\text { Depression was statistically associated with a } \\
\text { few personal, academic and interpersonal } \\
\text { factors of the nursing students surveyed }\end{array}$ & Level VI \\
\hline $\begin{array}{l}\text { Al- } \\
\text { Busaidi[201 } \\
1]\end{array}$ & $\begin{array}{l}\text { Undergraduate } \\
\text { Students } \\
{[n=81]}\end{array}$ & $\begin{array}{l}\text { The nine-item } \\
\text { depression } \quad \text { Patient } \\
\text { Health Questionnaire } \\
\text { [PHQ-9] }\end{array}$ & $\begin{array}{l}27.7 \% \text { of the students were found to have } \\
\text { depression, with female students at a slightly } \\
\text { higher frequency [30.7\%] than their male } \\
\text { counterparts [27.2\%]. } \\
\text { Similarly severe depression was also higher } \\
\text { among female students [19] than the nursing } \\
\text { students [14] } \\
\text { The percentage of depression reported among } \\
\text { medical and nursing students was lesser [17\%] } \\
\text { than the mean percentage generated for the } \\
\text { entire group of university students [27.7\%] } \\
\text { Symptoms commonly reported by the } \\
\text { depressed group was delineated }\end{array}$ & Level VI \\
\hline
\end{tabular}

Most (5 out of 6) of the studies examined the depressive states of nursing students. Perceived stress and clinical practice stress was each introspected in 2 different studies. The effect of spiritual learning program was tested in the study with quasi experimental design. The potential risk factors and selected demographic and academic variables which contributes to depression among nursing students were ascertained in 2 of the selected articles. The population in five of the selected studies were purely nursing students. The study done in Oman had students from the university which included $8.6 \%$ of medical and nursing students. The sample size in these studies ranged between 85 to 729 students. Depression scales were predominantly used, stress scales was used in 3 of the six selected studies. Spiritual well-being was examined in 2 of the studies. Self-esteem, anxiety and social support was surveyed in one study.

The range for depression scores ranged from normalcy to about $64 \%$. The highest mean score was reported among nursing students in India and the least was documented for the Korean nursing students. Stress 
scores were lesser for nursing students who were exposed to a spiritual learning program. The same group of nursing students also demonstrated higher clinical practice scores than their counter parts who were not exposed to the spiritual learning program. The study done among Korean nursing students revealed that, students with higher scores for existential, religious and spiritual wellbeing were satisfied with nursing as their major of study, and were optimistic for their employment in the future. An overview on the relationship of depression among Asian nursing students with other factors revealed that depression scores were positively correlated with stress and negatively correlated with spiritual well-being, self-esteem and social support.

A number of variables which either contribute or diminish depression among Asian nursing students were also delineated from the articles surveyed. They have been categorically represented in Table 3.

Table 3:Variables which affect Depression among Asian Nursing Students

\begin{tabular}{|l|l|l|}
\hline Academic factors & Personal factors & Interpersonal factors \\
\hline Better academic performance & Feeling better for career prospects & Better interpersonal relationship \\
Less academic stress & Higher frequency of exercise & Educational level of father of more than 9 \\
Greater interest in majors & $\begin{array}{l}\text { Enjoying their full right to make decisions } \\
\text { yigher self-evaluated score of health status } \\
\text { Preoccupied in love relationships }\end{array}$ & $\begin{array}{l}\text { Better relationship with parents } \\
\text { Higher sum scores of attained social support } \\
\end{array}$ \\
& & Familial disharmony \\
&
\end{tabular}

A major revelation in this literature survey was the unmasking of the subjective cues for predicting depression among this age group of students. The most commonly cited verbatim by depressed students were feeling down, depressed or hopeless; trouble concentrating; watching television; trouble falling or staying asleep or sleeping too much and suicidal thought

\section{Discussion}

The conceptualizations crystallized from these studies yielded three significant themes.

The key to curbing this disorder among student nurses is with Nursing Educators:Expanding the insight of the nurse educators on the high prevalence of depression among nursing students and its manifesting signs, will aid them in identifying the disorder at any early stage and provide prompt referrals.Nurse educators have an opportunity to meet prospective nursing students in career fairs conducted for high school students. These opportunities provide a platform for them to comprehensively state the attitudes and attributes required for the profession. Such forums should incorporate live chat with professional nurses and display videos in which nurses utilize their higher cognitive, affective and psychomotor domains. Conception of the precise professional values will instigate those with such virtues to consider nursing as their career. The end result of such selfintrospection will nominate a crystallized group of students with stronger academic achievements for nursing. This can also be ensured by pre-admission tests which tests the cognition, aptitude and attitude of the students whose career choice is nursing.

The transition from high school to nursing program demands the nursing students to a world of professional standards, which emphasizes on discipline, commitment and accountability. This sudden turn of events in a youngster's life could be stressful. This call for nurse educators to pay more attention to the novice professional through assignment of faculty as a mentor, guide and counselor; provision of structured orientation programs and tagging a senior nursing student with the novice. These strategies will provide opportunities to disseminate information on managing academic stress.

Self-preparedness of the nursing students:Depression is an experience traversed by an individual who is unable to cope with life's expectations and challenges. This calls for the individual to be boosted with the insight of one's own strengths and weaknesses. A need to accelerate the strengths and take remedial measures to overcome the weaknesses are achieved by improving one's own self esteem. Workshops, seminars and self-help kits which focus on 'self-esteem' are to be initiated and implemented by the teaching institutions. The core themes in these sessions will include self-awareness of one's own needs and wants, initiating self-care habit such as regular exercise, healthy eating habit, and modifying negative thoughts into positive ones.Spiritual up gradation changes a person's perception of stress, as a challenge or meaningful event. This change in thought process not only improves their work potential but also helps them to grow professionally. Proliferating the awareness and practice of stress management strategies among nursing students has been cited in literature to lower prevalence rates. Stress management strategies which has been proved effective includes regularly using relaxation techniques such as a deep breathing exercise, maintaining a positive attitude, learning to set appropriate boundaries, and getting enough sleep. Acquainting nursing students to these strategies in group discussions will foster among the students the feelings that they are not the only one facing hardships, further more they will also gain awareness on best practices to alleviate stress. These sessions will also nurture a strong social system in which psychologically underprivileged students can identify individuals with whom they feel supported, and also favors them to spend quality time with those individuals whom they trust. 
Evolution of a holistic system to help nursing students adapt to the profession: The summation of the above deliberations recommends the need to establish a support system which comprehensively caters to the emotional well-being of nursing students. The system should undertake pre-admission counseling and entry level screening; orientation and mentoring services for the novice learner; ongoing workshops on stress management strategies and constant surveillance of nursing students' emotional health. Involvement of the family in this undertaking will help to untangle the constraints within the family which has been reported frequently in literature to impose emotional crisis to the nursing students.

The Prevent-Predict-Prescribe model (Figure 1) integrates and illuminates the core themes discussed above. By applying this model in nursing programs, the penetrating roots of depression can be uprooted and healthier seeds of self-confidence, self-esteem and self-actualization behaviors can be promoted. These virtues can bring forth enriched nursing students who will demonstrate stronger professional values of accelerated competence, commitment and collaboration.

Figure 1: Prevent - Predict - Prescribe Model for Defeating Depression among Asian Nursing Students

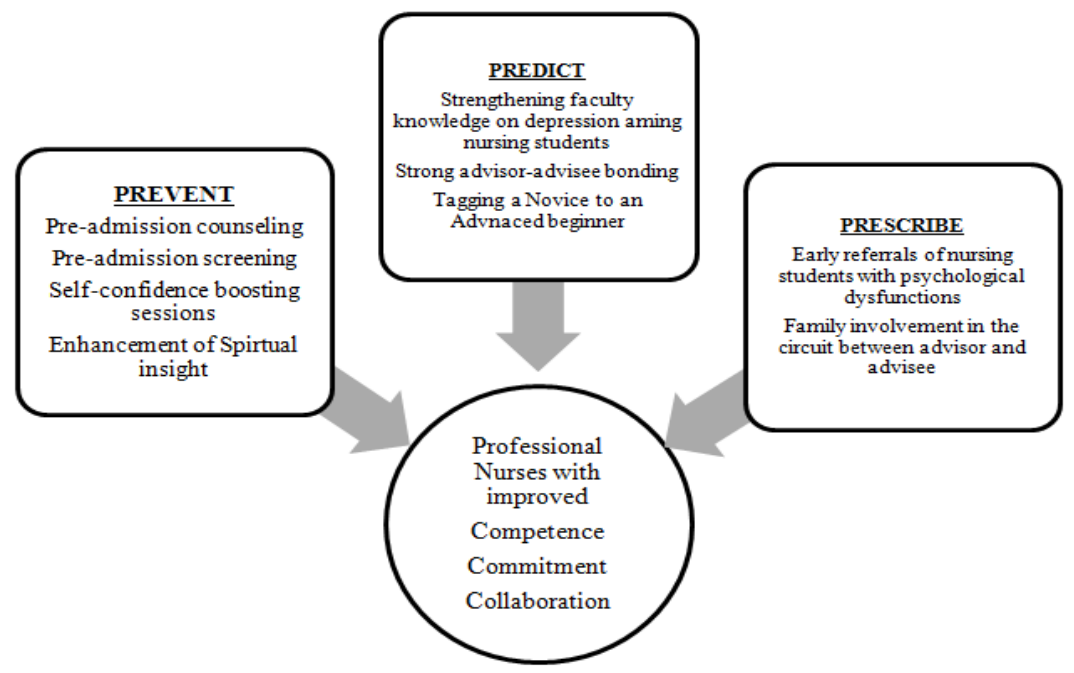

\section{Conclusion}

A need to implement and explore this model as a whole or as individual components in the Asian context is the word left behind for nurse researchers. Implications for the teaching community is well elaborated in the discussion. With regard to clinical practice, similar models can be developed to strenghen the emotonal well-being of professional nurses. Minor modifications in teacher-student interactions can make a world of difference to a novice learner and can maximize their emotional resources, which is a much needed attribute for professional nurses. Hence the role of nurse educators is magnified to detect and direct psychologically impaired nursing students.

\section{Reference}

[1]. WHO. Media Centre: Depression Fact sheet N`369 [Internet]. World Health Organization; 2012.

[2]. Statistics FIFoCaF. Major Depressive Episode. America's Young Adults. Washington, DC: U.S. Government Printing Office; 2014.

[3]. Perou R, Bitsko RH, Blumberg SJ, Pastor P, Ghandour RM, Gfroerer JC, Hedden SL, Crosby AE, Visser SN, Schieve LA. Mental health surveillance among children-United States, 2005-2011. 2013 Contract No.: Suppl 2.

[4]. Joiner T, Coyne J, editors. The interactional nature of depression. Washington, DC: American Psychological Association; 1999

[5]. Beasley PJ BW. Depression in the adolescent patient. Adolesc Med 1998;9:351-62.

[6]. Faris S. Teenage Depression: Statistics, Treatments, Symptoms, \& Diagnosis. 2012; Available from: http://www.healthline.com/health/depression/teenage-depression.

[7]. Deykin EY, Buka SL, Zeena TH. Depressive illness among chemically dependent adolescents. American Journal of Psychiatry1992;149:1341-.

[8]. Brown RA, Lewinsohn PM, Seeley JR, Wagner EF. Cigarette smoking, major depression, and other psychiatric disorders among adolescents. Journal of the American Academy of Child \& Adolescent Psychiatry1996;35(12):1602-10.

[9]. Moscaritolo LM. Interventional strategies to decrease nursing student anxiety in the clinical learning environment. Journal of Nursing Education2009(48):17-23.

[10]. Altiok H, Üstün B. The stress sources of nursing students. Educ Sci Theory Pract [Internet]. 2013 [cited 2013 Nov 10]; 13 (2): 760 6. 2013.

[11]. Magnussen L, Amundson MJ. Undergraduate nursing student experience. Nursing \& health sciences2003;5(4):261-7.

[12]. Ratanasiripong P. Mental health of muslim nursing students in Thailand. International Scholarly Research Network2012;2012. 
[13]. Chatterjee S, Saha I, Mukhopadhyay S, Misra R, Chakraborty A, Bhattacharya A. Depression among nursing students in an Indian government college. British Journal of Nursing2014;23(6):316-20.

[14]. Xu Y, Chi X, Chen S, Qi J, Zhang P, Yang Y. Prevalence and correlates of depression among college nursing students in China. Nurse education today2014;34(6):e7-e12.

[15]. Al-Busaidi Z, Bhargava K, Al-Ismaily A, Al-Lawati H, Al-Kindi R, Al-Shafaee M, Al-Maniri A. Prevalence of depressive symptoms among university students in Oman. Oman medical journal2011;26(4):235.

[16]. Lee Y. The Relationship of Spiritual Well-Being and Involvement with Depression and Perceived Stress in Korean Nursing Students. Global journal of health science2014;6(4):p169.

[17]. Hsiao Y-C, Chiang H-Y, Lee H-C, Chen S-H. The effects of a spiritual learning program on improving spiritual health and clinical practice stress among nursing students. Journal of Nursing Research2012;20(4):281-90. 